This item was submitted to Loughborough's Research Repository by the author.

Items in Figshare are protected by copyright, with all rights reserved, unless otherwise indicated.

\title{
For public communication: Promises and perils of public engagement
}

PLEASE CITE THE PUBLISHED VERSION

http://dx.doi.org/10.1080/13183222.2017.1288779

PUBLISHER

( EURICOM. Published by Taylor and Francis

VERSION

AM (Accepted Manuscript)

PUBLISHER STATEMENT

This work is made available according to the conditions of the Creative Commons Attribution-NonCommercialNoDerivatives 4.0 International (CC BY-NC-ND 4.0) licence. Full details of this licence are available at: https://creativecommons.org/licenses/by-nc-nd/4.0/

\section{LICENCE}

CC BY-NC-ND 4.0

\section{REPOSITORY RECORD}

Downey, John. 2019. "For Public Communication: Promises and Perils of Public Engagement”. figshare. https://hdl.handle.net/2134/25101. 


\title{
For Public Communication: Promises and Perils of Public Engagement
}

\author{
John Downey, Professor of Comparative Media Analysis, Director, Centre for \\ Research in Communication and Culture, Loughborough University \\ j.w.downey@lboro.ac.uk
}

\section{Introduction}

Michael Burawoy in his 2004 Presidential Address to the American Sociological Association made an impassioned argument for the rebirth of a public sociology. Burawoy's address provoked heated debate in sociology and in some other fields and disciplines (such as geography and criminology) and across countries. Burawoy's provocation has, however, been largely overlooked by scholars working in the field of communication and media, perhaps surprisingly given that the field draws (or at least drew) heavily upon sociological thought. In this article I will make an argument for public communication research. I will do this initially this through reviewing Burawoy's address. I will then discuss the impact of the Research Excellence Framework on public communication research in the UK, a development that I consider to be so far, on the whole, positive for the field of communication and media research. Finally, I will discuss what 'good' and 'bad' public communication research might be and what some of the difficulties are in conducting critically-informed public communication research.

\section{Burawoy's Eleven Theses}

Burawoy contends that the founding voices of sociology - Marx, Weber, Durkheim, Du Bois, Addams - sought to 'salvage the promise of progress' from the ruins and fragments of modernity (2005: 5). That moral and political purpose to change the world for the better, however, has been mislaid: 'If our predecessors set out to change the world we have too often ended up conserving it. Fighting for a place in the academic sun, sociology has developed its own specialised knowledge'(2005:5). This is Burawoy's complaint; that the professionalisation of sociology has led to a decline of moral and political purpose and that sociologists should strive to recover such purpose as a complement to the benefits of professionalization.

Burawoy then proceeds to offer eleven theses that chart and explain the development of the discipline, many of which are relevant to other social science disciplines and fields. It is worth reviewing these theses briefly. Thesis one is the 'scissors movement': the members of the profession have shifted to the left politically while society has shifted to the right at least 
in terms of the dominance of the market over the last 50 years. Thesis two is that there are multiple public sociologies, from the traditional (sociologists whose work in long or short form is read beyond the academy as intellectuals operating in the public sphere) and the organic where sociologists work with a public in a dialogic process of mutual education. To better pursue public sociology one needs, Burawoy astutely observes (but does not provide), a sociology of publics 'to better appreciate the possibilities and pitfalls of public sociology'(2005: 8). Public sociology, he argues, implies no specific political or value commitments on the part of the sociologists beyond a readiness to engage in dialogue with publics. Burawoy's third thesis is that there should be a sociological division of labour between professional, critical, policy and public sociology, which all have their rightful place in a flourishing discipline. Policy sociology is 'in the service of a goal defined by a client' (2005: 9). Both public and policy sociology are reliant upon professional sociology that provides a bedrock of knowledge, theories, methods while critical sociology examines the foundations of professional sociology questioning its normative assumptions. Critical sociology poses the questions of 'sociology for whom?' and 'sociology for what? that can be equally posed of communication research. Whose interests does communication research serve? What purpose does it serve? In Burawoy's ideal world these four sociologies should exist in a harmonious and mutually supportive relationship where developments in one can inform progress in another. The reality, of course, as he recognises, is that they often disrespect each other. This is a product of each not recognising the complexity and value of the other and this leads to thesis four that each type should try harder to understand the others. Thesis five recommends that we locate the sociologist and understand the pressures that lead to being located in one place and not another either inside or outside the academy or in relatively privileged tenured positions in highly ranked departments or as adjunct professors paid by the course (or even by the hour as is often the case, sadly, in the UK). Thesis six argues that each of the four types of sociology has its own normative assumptions and its own pathologies and that proponents of each type need to recognise the contributions each type can make to the vitality and flourishing of the discipline while thesis seven points out that the discipline is a field of power and one in which instrumental knowledge or professional sociology prevails over reflexive knowledge or critical sociology and that one of the consequences of instrumental knowledge is the "balkanisation of disciplines' (2005: 18). Critical and public sociology are the subalterns to professional and policy sociology. Burawoy argues that they should be allowed 'breathing space' so as to be able to revitalise professional and policy sociology (2005: 18). Thesis eight explores how professional sociology assumed its place in the hierarchy over three phases from the mid$19^{\text {th }}$ century onwards from the essentially public foundations to a mid -20 th century reliance on state and commercial funding to the critical sociology of the 1960s and 1970s. Thesis 
nine examines the power that American sociology can exercise over other national sociologies, sometimes to their disadvantage. Thesis ten discusses disciplinarity looking at the ways in which there can be cross-disciplinary borrowing, multi-disciplinary collaboration, trans-disciplinary transfusion, and joint-disciplinary coordination. In his eleventh thesis Burawoy outlines what he sees as the unique identity of the sociologist, the sociologist as partisan advocate and defender of civil society, or 'the lifeworld' in Habermasian terms, against encroachments by the market on the one hand and the state on the other. Informed by professional sociology it is driven by a 'critically disposed public sociology'(2005: 25). Burawoy ends his essay by discussing how incentives need to be put in place to encourage and recognise public sociology and that criteria need to be developed in order that we may distinguish between 'good' and 'bad' public sociology. This article stems from my agreement with much, if not all, of Burawoy's analysis. While there is much to say about Burawoy's characterisation of the discipline, the translation of his analysis to other disciplines and fields, and, in particular, the overplayed distinction between policy and public sociology which is based on a too narrow conception of what is public, it is to these two issues that I will now turn and discuss with reference to public communication research in the remaining sections of this article.

\section{Public Communication Scholarship}

Burawoy's address has been widely cited since 2004 with around 1500 citations according to Google Scholar (as of December 2016). While most debate has taken place, as would be expected, within sociology there has been debate across a number of adjacent social sciences such as geography, anthropology, criminology, social policy, and management. I will not attempt to summarise the reaction to Burawoy's essay here or give an account of his subsequent work in this area. The purpose of mentioning the substantial reaction to the essay rather is to highlight an absence. There has been either no or little engagement (to the best of my knowledge) with Burawoy's essay from communication and media scholars. Noone has written an essay called something like For Public Communication (until now) in a manner that has happened in other social science fields and disciplines. I find this surprising given what I hoped was the continuing importance of sociological thinking to the field of communication and media. What it points to perhaps is a growing intellectual independence, for good and bad, of the field of communication and media. Perhaps the 'field' is becoming a 'discipline' with its own canon of theorists? Perhaps the 'field/discipline' is becoming increasingly professionalised, anxious to secure its own place in the 'academic sun' to the detriment of public communication research? Fretting over its status both within the 
academy and as a publicly respected field of inquiry perhaps scholars have been keen to emphasise their professional credentials at the expense of both critical and public communication research? Whatever the reason the lack of engagement with Burawoy's call to public sociology from communication and media researchers now is a very good time to take up the debate and from a relative position of strength given the success of national and international professional communication associations such as IAMCR, ECREA and the ICA.

At the end of his paper Burawoy asks how can public sociology be encouraged in the academy through, for example, including public engagement as a criterion of promotion. In the United Kingdom we have the Research Excellence Framework (REF) where the research of departments across all subjects is periodically assessed by peers in order to distribute research funding. This is part and parcel of an audit culture that has swept over British universities in the last thirty years or so with often unintended and/or irrational consequences both for research and teaching. Controversially, however, I will argue that the inclusion of 'impact' for the first time in the 2014 research assessment as well as judgments concerning quality of publications and research environment is, on the whole, a positive move that has encouraged both policy and public communication research in the UK. Departments are now rewarded financially for their 'impact' and colleagues are rewarded at an individual level for their policy and public work.

When 'impact' was first suggested as a possible category in research assessment there was considerable opposition from social scientists and humanities scholars fearful that what impact meant was solely or primarily instrumental research of benefit to UK PIc or the state serving to entrench and legitimate inequality rather than combat it. This was viewed as an unwelcome invitation to hitherto critical scholars to participate in the colonisation of civil society or the lifeworld. Thanks in part to a successful rearguard laction 'impact' has come to Comment [J oT1]: Wording ?? mean something much broader that leaves some breathing space for critical public research including communication research. This, however, is no grounds for complacency.

The Higher Education funding Council for England define impact 'an effect on, change or benefit to the economy, society, culture, public policy or services, health, the environment or quality of life, beyond academia' (http://www.hefce.ac.uk/rsrch/REFimpact/). The assumption is that this 'effect' will be good but it is not specified what this good entails and how it will be measured. It was incumbent upon academics to demonstrate that they had an 'effect' on life outside academia through presenting evidence via a case study of how their research has 
been taken up and used in policy and broader public arenas. Each case study was then awarded a grade from 0 (unclassified) to $4^{*}$ (the highest grade denoting 'world-leading' impact).

As a field communication and media studies performed very well in assessments of impact in the 2014 exercise. Five departments stood out for their outstanding 'impact': LSE, Cardiff, Goldsmiths, King's and Westminster. To a certain extent geography and institutional hierarchy play a role here. Three of these universities are members of the prestigious Russell Group of elite UK universities. All are based in capital cities with four based in London with readier access to industry, regulators and policy-makers. The impact playing field then is hardly a level one but despite that I am going to argue that including a broad understanding of impact in research assessments has provided an incentive for colleagues across the UK to engage in policy and public work including critical policy and public work. One can find summaries of the 159 impact case studies submitted to REF 2014 in the field of communication and media studies here http://impact.ref.ac.uk/CaseStudies/Results.aspx?UoA=36.

Here are some of the titles that indicate that impact case studies can indeed be related to critical research: Bringing post-1968 feminism to life for new audiences: enriching public appreciation and understanding of the British Women's Liberation Movement; Changing economic thinking to enable the world's greatest museums to deliver digital images free of charge to everyone; Is Another Internet Possible? Power Struggles for Ownership and Control of Cyberspace; Empowering children online through literacy and safety initiatives.

While we do not know the 'impact scores' for individual case studies for departments (except for departments that had $100 \%$ of their case studies judged at $4^{\star}$ ) it is highly likely that case studies containing critically-informed scholarship scored well given the character of the case studies submitted by the 5 outstanding departments noted above. We have the REF panel for communication and media to thank for this in that they chose to recognise the excellent critical research that takes place in the UK and its reach beyond academia.

There were also case studies of course that were clearly instrumental in nature but the results of the REF 2014 exercise suggest that case studies that contained critical research were certainly highly valued. This means that there is breathing space for critical policy and public communication research in the UK. It is recognised and funded and there are incentives for researchers to engage in such work in terms of their careers as well as of course wanting to make the world a better place. The impact agenda then has served to 
counteract, perhaps paradoxically, some tendencies in the field towards 'professionalization' by making policy and public research part of professionalization. So this answers, at least for the UK, Burawoy's question about how to encourage public sociology or public communication research. So far, so good. However, we still have the question of the how to decide between 'good' and 'bad' public communication research.

\section{'Good' and 'bad' public communication}

To summarise the argument so far: Michael Burawoy's diagnosis of professional sociology and the call for a more public sociology can as well be applied to the professionalization of the field of communication and media research. However, in the UK the rise of the impact agenda has somewhat surprisingly led to the creation of some breathing space for criticallyinformed public communication research that seeks to bring about social change and has provided some encouragement to researchers.

I am now going to make the much more difficult argument that reflexive, critically informed policy and public communication research is 'good' and instrumental, professional policy and public communication research is 'bad'. Burawoy poses this as a question at the end of this 2004 but clearly he advocates a similar answer but without providing his grounds. We have to address the questions: communication research for whom? And: communication research for what? These questions are about the normative foundations of social science, professional, policy or publicly oriented.

I have tried to answer this question together with co-authors in recent years (see Downey [2008], Downey, Titley, Toynbee [2014], Downey and Toynbee [2016]) by making reference to the third and fourth generation of the Frankfurt School. Communication and media studies' engagement with the Frankfurt School seems to be restricted now either to Adorno and Horkheimer's classic culture industry essay or Habermas' early work on the public sphere with scholars overlooking the work of third and now fourth generation Critical Theorists such as Axel Honneth and Rainer Forst. The work of Honneth and, in particular, Forst provide vital resources for the repair of critical communication research.

Forst's project is to make political philosophy take a reflexive turn. The central question in political philosophy is the justification of political rule. Forst makes the question contextual and reflexive by asking who poses this question and who has the authority to answer it. The idea of discursive justice as fundamental is embedded in the posing of the question of 
legitimacy and this provides 'at once (a) substantial and procedural foundation of a just society' (2014: 3). Logically, claims to general and reciprocal validity can only be made good in a discursive context of generality and reciprocity. Claims to legitimacy presuppose the validity of a discursive context in which claims can be settled. This presupposed condition of reciprocity is Forst's key insight, which provides both the historical and a priori grounds for critique making traditional oppositions between immanent and transcendental critique superfluous. Forst regards persons as active agents in need of justifications requiring reciprocity i.e. equality in terms of engaging in debate and in decision-making about matters affecting their lives. For Forst this reciprocity is the 'first requirement of justice'(2014: 5). This both implicit and ideal notion of reciprocity provides the reference or vantage point from which we engage in critique of practices and forms of thinking that stand in the way of creating egalitarian forms of life. It guides the questions we ask, the analysis we engage in. According to Forst, to engage in critique is to undertake, following Honneth's expression, a pathology of reasons to ascertain how in specific times and places the unjustifiable is justified. The pathology always has to be anchored in a conception of what a healthy society is.

So we have reached the position that there are clear normative foundations (that communication research should be for 'the people' aiming to bring about relationships of reciprocity) and thus a clear moral imperative for engaging in critically-informed public communication research. Added to this in the UK at least there is institutional support to do so (and so moral purpose and self-interest of researchers potentially converge). While both the moral and institutional foundations for engaging in such research exist, there are obstacles to overcome and rapids to navigate. It is much more straightforward to identify and judge critically-informed research in itself than judge the impact of such research. Given that public communication researchers cannot control the impact their research because this is a consequence of how the research is received, there is the possibility of course that criticallyinformed public communication research that aims to change the world may have no, small or even unintended consequences because of the way that it is read and used by others. This is, of course, true also for 'value-free' professional communication research that, for instance, could be used by authoritarian regimes for the purposes of censorship. What are we judging here? The quality of the research, which is arguably more under the control of the researchers? The quality of the 'impact', which is much less under the control of the researchers? How do we judge the 'benefits' and indeed 'disbenefits' that accrue to society because of such research? If we are interested in judging 'public' sociology then the answer must be both: the quality of the research and the quality of the impact. While we as academics may be experts in judging the quality of research we know comparatively little 
about our publics and the impact of our research, not to mention the problem of what 'quality' might mean when thinking about impact.

Over the last 15 years or so I have with colleagues attempted to undertake critically-informed public communication research funded by a variety of public sphere institutions (newspapers, broadcasters, universities, regulators, research councils, arm's length state bodies) with the intention to change policy, practice and public attitudes as well as publish research aimed at academic audiences. The following anecdotes and musings are drawn from my personal experience of engaging in public research. They are of course inadequate as a basis for analysis but I hope that they may encourage others to do some 'proper' research about impact. They provide a potted backstory to the published public research. My experience may well chime with that of others. It will I hope be useful to others hoping to engage in such research. As my university, Loughborough, was not among the five leading departments in the field for impact in REF 2014 I am certainly not trying to offer a 'how to' guide for impact.

\section{Going Public: the possibilities and pitfalls of public research}

The best way to do this is initially to follow the argument of a recent essay by Herbert Gans (2016), an American sociologist who has written extensively about news media and popular culture as well as poverty and the city. He has also engaged extensively in public sociology and written about public sociology avant la lettre. Gans makes the crucial observation that ironically in the extensive debate about public sociology provoked by Burawoy 'almost all of it dealt with sociology, virtually ignoring the public and the role it plays in the realization of public sociology'(2016: 3). To begin to address this Gans sets his task as the examination of the process of the transformation of sociology into public sociology with a focus on what he calls 'presenters' - journalists, publishers, social media participants. They are research intermediaries that permit and restrict the access of researchers to 'the public'. Gans offers a series of hypotheses that need to be examined empirically arguing that such work is essential in realising the project of public sociology. Here, of course, we are precisely on the terrain of research in communication and media and this is an area in which scholars in our field could make a vital contribution to understanding the process of 'publicness' in the social sciences and humanities as a whole. While there is a considerable body of literature on the mediation of science there is surprisingly little on social science and the humanities (see Natalie Fenton, Alan Bryman, David Deacon and Paul Buckingham [1998]). If social scientists are to influence their publics and their presenters they must have greater knowledge of their audience. 
Gans focuses, as I will, on Burawoy's traditional public (rather than organic sociology) where sociologists' access to and interactions with 'the public' or rather publics is mediated by 'presenters' (the advent of social media use by academics does blur the boundaries somewhat between the traditional and the organic, which I will return to later).

Gans argues that researchers are often simply quoted by journalists or other writers to 'support or legitimate their work'(2016: 5) and that such contributions are too short to be considered public sociology. This is interesting because it potentially confuses two things: length and legitimation. If a journalist hunts out work of professional sociologists that happen to agree with the views of the journalist does that make it 'public sociology' if the quotes are lengthy? How about the work of others that journalists ignore because they do not fit with their views? When speaking to journalists it is often the case that what sort of article the journalist wishes to write and the line they wish to pursue becomes apparent and journalists will invite academics to say things that support the line of the article. The ethical thing to do as a public communication researcher is to tell it as it is but that often means being ignored in the published work. If there is pressure on researchers to become public then it presents them with an ethical dilemma when the approach that involves first educating the timepressed journalist tends to be unsuccessful.

Gans identifies four publics for public sociology: two groups are college students, one group is ex-students with elite tastes and the final group is the 'less educated public'. The student groups are either taking sociology courses or are taking courses where sociological literature is assigned reading. Elite ex-students are consumers of news and cultural media such as the New Yorker and The Atlantic. The 'less educated' group are by far the biggest group and by far the hardest to reach as they do not possess the educational background that helps to make sense of social issues and sociologists are not trained to write for such a group. While Gans' differentiation of the non-student public into essentially a small group of elite wealthy, urban and middle aged people and the rest is questionable to say the least it is undoubtedly true that we do not have a great deal of knowledge of what they might be interested in. The danger is that public sociologists will write for an 'ideal public' that may not exist and critically-informed public communication might be missing a public.

If professionals and publics are essential for public sociology presenters often act as an intermediary. 'Presenters' are people who 'sell their symbolic wares' to publics. This is an overly narrow view of presenters and one certainly formed by the essentially market-based media systems of North America. Many public service broadcast journalists would baulk at the description of peddling wares. It is true that it is increasingly unusual to find a public 
service journalist unconcerned about audience figures but that does not mean that journalists are selling anything rather than say informing.

Presenters fall into a number of categories: teachers, journalists, editors, book publishers, social media sites such as You Tube or Twitter. For the last category Gans appears to neglect the possibility of public sociologists themselves achieving a following from members of the public. In addition to the categories of presenters proposed by Gans there is another important one. Here there are organizations who wish to contract research work on a particular topic to help them achieve their objectives (for example, the BBC Trust exercising oversight over the $\mathrm{BBC}$ ) with subsequent reports published in paper or electronic form but aimed squarely at the public and at other presenters rather than at an academic audience. So not only do we need to understand potential broader publics but also these public intermediaries who act as gatekeepers to the broader public and who because of the importance of the impact agenda especially in the UK are beginning to exert influence over what research gets done. This may be good or bad.

\section{Handmaidens of Industry?}

The Centre for Research in Communication and Culture at Loughborough University has engaged in a media content analysis and a discourse analysis of national broadcast television and radio news programmes and national newspaper coverage of UK General Elections since 1992. In the early 1990s the issue of press 'bias' in particular was high up the public agenda. In 1992, for example, after a close fought election in which the Labour Party led for most of the way to be ultimately and surprisingly defeated by John Major's Conservative Party, The Sun newspaper famously claimed that "It was The Sun wot won it!'. During the Blair years, however, the Murdoch press backed the Labour Party, only changing allegiance again to the Conservative Party in 2010. In 1990s and early 2000s the CRCC received funding from a national newspaper to conduct a content analysis and the newspaper then published the research in short form with very little editorial input from the newspaper. Since then, however, the newspaper has decided not to fund the research and is reluctant to publish articles authored by academics. We continue to do the research and the issue has re-merged on the public agenda since 2010 and was prominent in the 2016 EU referendum but it is often the case that journalists use some of our data and then include some quotes from the research or from a telephone interview. A very large number of newspapers and broadcasters use our research but often in a way that, at least according to Gans' criterion, does not qualify it as public communication research as it would appear to legitimate a pre-existing narrative of the journalist rather than set the agenda (although this 
may well be an unhelpful binary way of thinking about publicness). At least for this research the climate seemed more hospitable twenty years ago in terms of column inches and the freedom given to academics to write for an elite public. We now, of course, self-publish our research on our website and tweet about it extensively (or rather the PR department with our help at the university tweet about it extensively). (It then gets picked up by external intermediaries; the process of publicness changes over time and the impact of 'new' and social media is substantial see Christopher Schneider and Deana Simonetto (2016) for an analysis of how sociologists interact with their publics via Twitter.)

This raises the issue of whether and, if so, how researchers should respond to the public agenda and/or presenters' agenda. One option when the newspaper funding ran out would have been to change tack and choose an issue higher up the public agenda so as to increase the chance of having impact. This 'ambulance chasing' approach that is encouraged by the impact agenda may result in researchers turning away from very important research that is not seen as being of public interest at the present time with academics encouraged to follow rather than leading the public agenda. This may mean that there is not always a harmonious, complementary relationship between professional and public communication research.

\section{Interests: Dispassionate and disinterested?}

The next anecdote comes from an interview for a piece of research that a well-known broadcaster wished to conduct about their coverage of a major international conflict with a considerable and complex history. One of the interviewers asked me to comment on the work of colleagues from a different university in the field who had recently published a book on the subject that was highly critical of the broadcaster in question. It was felt by the broadcaster that the academics concerned had been 'biased' and wanted an assurance that the CRCC would conduct a dispassionate, disinterested 'value-free' analysis. Such an analysis hardly fits with the idea of a critically informed public communication scholarship that is explicitly morally and politically engaged. Rather than engaging in a debate about the possibility and/or the desirability of value-free social science or engaging in an obviously desired criticism of colleagues I explained at some length our methodological procedures, coding schedules, inter-coder reliability tests and so on. It was of course not the answer that the broadcaster was looking for but we managed to secure the contract and to conduct critical and methodologically vigorous research that confounded dominant industry and popular perceptions. 


\section{Censorship and self-censorship?}

Looking back now at just over ten years distance what is remarkable is how little editorial control the broadcaster exercised over the analysis of how it and other broadcasters represented the highly controversial issue. We wrote a critical report and it was published on their website as we wrote it. A few years later we conducted some more research for the same broadcaster on a much less contentious issue but under a different oversight regime and we found that an extreme amount of editorial oversight was employed with numerous drafts being passed to and fro with substantial debate about the use of single words. The slightest implied criticism of the broadcaster was subject to intense scrutiny and we were 'encouraged' to change the way we expressed ourselves. Hovering in the background while these editorial conversations were taking place was the thought that this broadcaster would certainly commission future research that we would undoubtedly be interested in bidding for not just because it allows us to do large scale research but also because it allows us to demonstrate impact and reach a 'public' audience through publication on the broadcaster's website and attendant media coverage.

Although I have been unable to confirm this beyond reasonable doubt I have conducted a number of interviews with well-placed sources that suggest that one of the reports we undertook went down so badly with the management of a broadcaster that considerable time and effort was spent to 'kick the report into the long grass'. It is fair to say that the conclusions of this report did not agree with perceptions of the senior management of the broadcaster itself or of the mainstream news industry as whole in the UK. The report should clearly have had more impact than it did but this was nothing to do with the quality of the research.

\section{Public Ridicule and Vilification}

Of course, when research contradicts views widely held by presenters then it tends to be subject to ridicule and vilification with little or no right of reply in the UK at least. Certain of the criticism we have endured from national UK media institutions or prominent journalists I am happy to wear as a badge of honour. Several colleagues in the field in the UK have been subjected to unpleasant ad hominem attacks by press and broadcasters. While I do not wish to overplay these in a European context where academics are losing their jobs and even their freedom for engaging in criticism, such press criticism is clearly supposed to have a 
chilling effect on the public activities of academics critical of media institutions and practices in the UK.

\section{Speaking in Tongues: Academic, Policy and Popular Discourse}

One of the ways in which communication research can become public is through responding to government consultations on Green Papers and to Select Committee inquiries of the Houses of Parliament. A case in point is the recent Charter renewal of the BBC that witnessed the most concerted attack since the 1980s high-tide of Thatcherism on the universal principles of public service broadcasting by the present UK government. The government's Green Paper on the future of the BBC was framed in terms of public service broadcasting 'crowding out' private sector investment in media industries. In this worldview public service broadcasting should only produce content where there is 'market failure' i.e. in unprofitable programme genres.

Now how do we respond to this attack on public service broadcasting? One approach is to accept the terms of the Green Paper but argue that the presence of public service broadcasting encourages the private sector to 'up its game' leading to higher levels of programme investment: this is the 'crowding in' argument. Another approach is to seek to change the paradigm of the debate to one informed by welfare economics where it is conceded that the presence of public service broadcasting may crowd out private sector investment to some extent but that overall the level of investment is higher when there is both public and private sector investment together rather than simply private sector investment. Thus the welfare for citizens is optimised by the presence of both types of broadcasting. A third approach and potentially a radical argument would make a basic argument in favour of public service broadcasting because it is guided by the public interest rather than the profit motive and that all this talk of markets wrongly lumps together quite different types of broadcasting. It essentially argues that public rather than private broadcasting should be the default position so as to best serve the public interest.

A communication scholar engaging in the public sphere is clearly also a citizen engaging in a war of position to adopt Gramscian terminology. Assuming that the objective is to defend public service broadcasting then scholars not only have to work out what they believe (which argument is the strongest? What evidence is the strongest?) but also which argument is likely to be more effective given the context of its reception, which is likely to be hostile. Would the more radical argument get as favourable a hearing from Select Committees as one based upon a particular branch of economic inquiry? The answer to this question is 
'probably not'. In which case, this may act as an incentive for academics not to advance radical arguments as they are unlikely to have an impact. In the search for impact there is, therefore, a danger in self-censorship, in a narrowing of public debate, and of academic discourse mirroring discourses found in policy circles. Conversely, if academics do advance a radical argument there is the risk that they are not heard beyond the academy or counterpublics. Ideally, academics would advance radical arguments that are widely disseminated to the public and widely influential but it is not entirely clear how this is to be done and their prospects of persuading doubters.

\section{Media Effects? A life of their own}

The impact of research is judged according to its 'reach' and 'significance'. As I have argued the problem with this is that reach and significance is not simply a product of the research but depends upon the actions of presenters and publics. This can be problematic when presenters and publics who not only use research for their own purposes (which is of course to be expected and there is nothing intrinsically wrong in this) but can also misinterpret research (either intentionally or not). In 2016 CRCC conducted a media content analysis of national broadcast and press coverage of the EU referendum. We self-published weekly reports and tweeted extensively to publicise the reports (the tweets were mostly aimed at presenters who we hoped would like, retweet, talk about our research etc). This resulted in a great deal of media attention nationally and internationally. Two aspects of our research were picked up in particular. One was the remarkable absence of female voices from the public debate. This was highlighted by Harriet Harman and prompted a letter to Ofcom, the UK's communication regulator, about the representativeness of the UK media. This accurately reflected our research findings. The second case though was much more problematic. Our research showed the Conservative dominated, 'Blue on blue' nature of the mediation of the referendum campaign served to largely squeeze out representatives of other parties, including the Labour Party. Jeremy Corbyn, the Labour leader, appeared much less often in TV and newspapers than Cameron, Johnson, Osborne, Gove and, indeed, Farage. This finding was then picked up by anti-Corbyn Labour supporters to argue that Corbyn had campaigned in an half-hearted fashion and was therefore partly responsible for the Brexit vote. Subsequently, our findings were picked up by Corbyn supporters to argue that because he appeared more frequently than other Labour Party politicians in the campaign that he did a great job of campaigning. Both positions unfortunately are unwarranted extrapolations from our research findings. Corbyn's relative absence or presence in national media news cannot be accounted for by his performance in the 
campaign alone but is indicative of media performance during the campaign and the choices journalists made about whom and what to cover. How Corbyn may or may not have contributed to his mediation is a complex issue. However, in the highly charged political recriminations in the aftermath of the Brexit vote it was very difficult to get this message across.

\section{Conclusion}

In this article I argued that Burawoy's eleven theses on public sociology are highly relevant to the field of communication and media. His claim that the process of professionalization of sociology has meant that academics have unduly turned away from public sociology is mirrored in the field of communication. This is not a desirable situation even if there are undoubted benefits from the process of professionalization and the achievement of a place in the 'academic sun'. I then argued that in the UK at least the introduction of the impact agenda to the Research Excellence Framework in 2014 has, on the whole, had positive effects for public communication research in that academics are now rewarded for engaging in such research. However, we now need to move the debate on in two ways. The first is normative: what do we mean by 'good' and 'bad' public communication research? I made the argument that the basis for good public communication research is research founded on the principles of reciprocity and equality. In addition, 'reach' and 'significance' need to be problematized as criteria of impact through a critical engagement with the process through which research becomes public: public research for whom and for what?

Communication scholars could potentially make a vital and unique contribution to understanding the process of the becoming public of academic research generally by highlighting the role of presenters and publics. Some presenters and some publics are more willing to engage with critically-informed research than others. Some presenters look for instrumental research that they then use to confirm their own positions and legitimate their own practices. Rather than promoting outcomes that contribute to the realisation of reciprocity and equality, the research is in danger of legitimating inequalities or being used to legitimate inequalities. In a climate where academics are rewarded professionally for 'impact' and where some presenters are keen on instrumental research, we must be careful to ward off the danger of public communication research becoming a servant to the interests of presenters rather than serving the public interest. The best way of doing this is to raise normative questions insistently when engaging in both professional and public debate.

\section{References}


Burawoy, Michael. 'For public sociology' American Sociological Review 70(1) 4-28.

Downey, John. (2008) 'Recognition and the renewal of ideology critique' in Hesmondhalgh, David and Toynbee, Jason eds The Media and Social Theory, Routledge: London. ISBN: 978-0-415-44800-0.

Downey, John., Titley, Gavan. and Toynbee, Jason. (2014) 'Ideology Critique: the Challenge for Media Studies' in Media, Culture and Society 36(6) pp878-887.

Downey, John. and Toynbee, Jason. (2016) 'Ideology: Towards Renewal of a Critical Concept' in Media, Culture and Society 38(8) pp1261-1271

Forst, Rainer. (2014) Justification and Critique. Cambridge: Polity

Gans, Herbert. J. (2016) 'Public Sociology and its Publics' American Sociologist 47 3-11

Fenton, Natalie, Bryman, Alan, Deacon, David \& Birmingham, Paul (1998) Mediating Social Science. London: Sage.

Schneider, Christopher \& Simonetto, Deana (2016) 'Public Sociology on Twitter: A Space for Public Pedagogy?' American Sociologist doi:10.1007/s12108-016-9304-2 